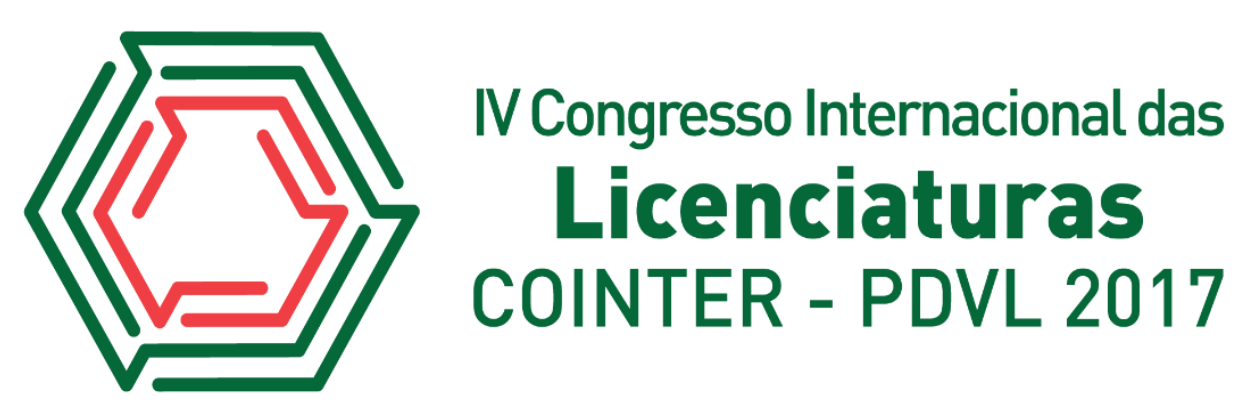

\title{
ANÁLISE DO CONHECIMENTO A CERCA DO EXTRATIVISMO VEGETAL NA AMAZÔNIA POR ALUNOS DO ENSINO FUNDAMENTAL
}

\author{
Apresentação: Pôster
}

\begin{abstract}
Camila Cristina Soares Lobato ${ }^{1}$; Bruna Oliveira Ferreira ${ }^{2}$; Darleny Cristina Serrão Penisch ${ }^{3}$; Andrea Masae Dos Santos Okabe ${ }^{4}$; Ruth Helena Cristo Almeida ${ }^{5}$
\end{abstract}

\section{Introdução}

No contexto atual, a crise ambiental mundial e suas inúmeras justificativas, tem de certa forma estimulado o reconhecimento da diversidade social que compõe a região amazônica. Uma temática muito discutida por acadêmicos, cientistas e porta-vozes do governo, movimentos sociais e empresas, é a necessidade do repensar o uso da biodiversidade, agregando valor aos produtos extrativistas e valorizando o conhecimento tradicional dos povos da floresta (GONÇALVES, 2001).

O extrativismo se refere não apenas à gestão dos recursos naturais e ao uso da biodiversidade, mais também sobre o conhecimento tradicional dos povos e populações, principalmente das comunidades tradicionais, ribeirinhos, indígenas, quilombolas que fazem uso de tais recursos (SILVA, 2016). O extrativismo vegetal também faz parte de um processo histórico, na Amazônia essa atividade foi marcada por ciclos, sendo o mais importante que alavancou a economia do País, o ciclo da borracha. Também, a extração da madeira, marcado historicamente pelo Pau- Brasil, assim como a extração da castanha, óleos, sementes etc. que são protagonistas do mercado atual (HÉBETTE, 2004).

Desta forma o presente trabalho teve como objetivo levantar dados acerca do conhecimento de "Extrativismo vegetal na Amazônia" por alunos do $7^{\circ}$ ano de uma escola pública de Belém do Pará, buscando identificar as dúvidas mais frequentes dos alunos a acerca da temática, especificamente compreender o discurso dos atores sobre o conceito de extrativismo, desenvolvimento e sustentabilidade na Amazônia e comparar os discursos desses grupos de atores com a literatura para verificar como esses discursos se alinham à definição de Extrativismo, e por

\footnotetext{
${ }^{1}$ Engenharia Florestal, Universidade Federal Rural da Amazônia, milacristina2@gmail.com

${ }^{2}$ Engenharia Florestal, Universidade Federal Rural da Amazônia, bruhdantas17@gmail.com

${ }^{3}$ Engenharia Florestal, Universidade Federal Rural da Amazônia, darlenypenisch@gmail.com

${ }^{4}$ Engenharia Florestal, Universidade Federal Rural da Amazônia, okabe.florestal@gmail.com

${ }^{5}$ Docente, Universidade Federal Rural da Amazônia, ruthpara@yahoo.com.brl
} 
fim, oferecer uma cartilha explicando sobre Extrativismo abordando as deficiências, e dúvidas encontradas ao longo da pesquisa buscando uma melhor abordagem para a compreensão dos atores.

\section{Fundamentação Teórica}

A origem do próprio território e população em que vivemos, dada a significância da atividade extrativista para a região, se faz necessário esclarecer essa importância, já que Rêgo (1999) afirma que: "A especificidade da Amazônia, quanto à intervenção das populações tradicionais nos ecossistemas naturais, é a diversificação do uso dos recursos em sistemas de coleta, cultivo e criação de animais. Tais sistemas de manejo estão fundados na cultura tradicional das populações amazônicas, que favorecem uma relação harmônica com a natureza".

O extrativismo vegetal é abordado em sala de aula no ensino fundamental, dada à importância desse assunto na atualidade. Levando em consideração as constantes transformações sofridas pelo meio ambientes. Dessa forma é possível discutir teoricamente, o que precisaria ser considerado na educação ambiental como ferramenta de transformação social, frente aos desafios de agregar o conhecimento sobre o extrativismo vegetal, que por uns é vista como uma estratégia de desenvolvimento para a Amazônia e para outros como a degradação e com um fím em si mesmo (SILVA, 2014). O pensamento educativo dominante, que influencia profundamente propostas pedagógicas implantadas em atividades de educação ambiental em Unidades de Conservação, é marcado por uma visão que afirma como verdade o princípio segundo o qual nos desdobramos na história por meio de determinações essenciais. Com isso, a ação prática não tem sentido condicionante e nem a realidade histórica pode ser alterada pela atividade de nossa espécie (LESSA, 2001).

\section{Metodologia}

A primeira etapa do estudo deu-se através do levantamento bibliográfico específico sobre o extrativismo vegetal, desenvolvimento, sustentabilidade, diversidades e sobre as comunidades tradicionais (ribeirinhos, indígenas e quilombolas). A segunda etapa foi o levantamento de informações sobre os alunos da escola estadual de ensino fundamental e médio "Fé em Deus" localizada em Icoaraci, distrito de Belém do Pará, visitas in loco, registros fotográficos, e obtenção de dados primários para a elaboração do questionário de acordo com a ementa da disciplina de estudos amazônicos aplicada para alunos do $7^{\circ}$ ano do ensino fundamental. 
O questionário aborda as competências da proposta curricular da disciplina de estudos amazônicos que apresenta os objetivos de: Refletir sobre a relação dos homens com a natureza, a partir da observação da realidade que o cerca; Reconhecer o ser humano como agente social que integra o espaço geográfico; Analisar o processo de construção histórico da região paraense. A terceira etapa consistiu em na análise dos dados dos questionários aplicados contendo 10 perguntas subjetivas referentes ao tema "Extrativismo na Amazônia: limites socioambientais" para 20 crianças do período vespertino e em seguida fez-se o desenvolvimento do produto na forma de cartilha de acordo com as deficiências encontradas nos resultados dos questionários.

\section{Resultados e Discussões}

Quando questionado o conceito de extrativismo vegetal, os entrevistados definiram como a extração/retirada dos recursos naturais da floresta para serem vendidos ou industrializados ou para sua própria subsistência. De todos os entrevistados, percebeu-se a concordância com Silva (2014), pois o mesmo diz que o extrativismo, enquanto atividade humana é caracterizada por ações realizadas e produtivas inseridas a diferentes questões socioeconômicas, agronômicas e ambientais. Com uma abordagem política, o conceito mais usado é o do IBGE, o qual diz que o extrativismo é a “[...] exploração dos recursos vegetais nativos através da coleta ou apanha de produtos, que permite a produção sustentada ao longo do tempo, ou de modo primitivo e itinerante, possibilitando, geralmente, apenas uma única produção” (IBGE, 2002, p. 49).

Já a pergunta que abordava a importância da atividade não obteve resposta satisfatória, tendo uma compreensão apenas econômica. Os percentuais de 100\% dos alunos concordam que a extração é importante para a encomia para qualquer comunidade. Porém, Homma (2012) destaca que além da importância econômica, há a sustentabilidade biológica que garante a sustentabilidade econômica e vice-versa. Na discussão sobre os extrativistas, populações tradicionais que desenvolvem essa atividade e motivação dos mesmos, dos 20 entrevistados, $75 \%$ dos alunos responderam que os povos tradicionais utilizam o extrativismo para se sustentar (subsidio econômico), e o restante dos alunos disseram que usam os recursos para a sua sobrevivência (subsistência). Portanto, 75\% dos entrevistados está de acordo com a teoria de Rêgo (1999), que diz: "O modo de vida tem sua matriz na dependência e simbiose com a natureza, no conhecimento empírico e simbólico dos ciclos e recursos naturais, e tal saber é à base dos sistemas de manejo de baixo impacto praticados".

Quando questionado sobre a importância das populações extrativistas, $60 \%$ dos 
entrevistados disseram que as comunidades extrativistas são importantes para exploração de recursos da Amazônia, 25\% não souberam responder à pergunta e o restante afirmou que são importantes, pois participam da economia da região. Dada à importância, questionou-se o entendimento dos atores sobre o "Ciclo da Borracha", e dos 20 entrevistados, $20 \%$ disseram que o período foi importante para a Amazônia, 30\% responderam que foi importante economicamente e o os $50 \%$ não souberam responder. Sobre práticas extrativistas, os atores já tiveram oportunidade de conhecer alguém que exerça a atividade extrativista, $45 \%$ dos alunos não conhecem nenhuma comunidade tradicional e 55\% já estiveram em uma ou possui familiares no local, o que reafirma a proximidade da temática com a vida dos atores.

$\mathrm{Na}$ abordagem discursiva sobre a passagem de conhecimento de geração para geração nas comunidades tradicionais, $85 \%$ dos entrevistados disseram que o conhecimento passa de geração em geração, $10 \%$ não souberam responder e o restante disse que o conhecimento passa por meio da religião. Resposta satisfatória já que o extrativismo é, portanto, uma construção social realizada ao longo de gerações, promovendo acúmulos de saberes, constituindo-se em um objeto de estudo complexo. Constata-se, tanto em nível teórico quanto em nível aplicado, uma reflexão insuficiente acerca do extrativismo, sob a ótica da abordagem sistêmica (SILVA, 2014). Sobre o interesse dos alunos pela temática, podemos afirmar que todos os entrevistados se interessam pelo assunto. Percebe-se então o interesse por conhecer mais sobre o assunto quando demonstrado que a temática está ligada a realidade de cada um.

Na discussão sobre a relação entre extrativismo vegetal e a sustentabilidade, dos 20 alunos, $60 \%$ responderam que a sustentabilidade está relacionada aos cuidados que temos que ter com a floresta, 30\% disseram que o extrativismo está ligado a subsistência e o restante não souberam responder. Conceitos que podem ser comparados como o de Homma (2012), que afirma que a sustentabilidade do extrativismo vegetal também depende do mercado de trabalho rural, no qual, com a tendência da urbanização, a população rural está perdendo não só seu contingente em termos relativos, mas também em termos absolutos. Logo, o que podemos fazer é, por intermédio da educação, ajustar os nossos comportamentos para garantir o bom funcionamento da sociedade e a harmonia com a natureza. 


\section{Conclusões}

Constatou-se ao longo da pesquisa que as deficiências mais pertinentes são quanto à importância cultural e histórica da atividade extrativista para a Amazônia, e a relação com a realidade de cada um. Os alunos entendem essa temática como algo distante do seu cotidiano, sendo necessária a contextualização desse assunto com exemplos locais para melhor compreensão. Além disso, observou-se que a percepção quanto ao Extrativismo Vegetal é meramente econômica, dada a deficiência do conhecimento da importância cultural e histórica da atividade mais uma vez. A atividade é vista somente como fonte de lucro para o trabalhador rural, sem a abordagem da atividade como tradicional desenvolvida a séculos na região. Diante do exposto, em vista das respostas insatisfatórias e fora de contexto que tivemos na maioria das questões apresentadas, é possível afirmar que a escola "Fé em Deus" não está atingindo os objetivos da ementa da disciplina de "Estudos Amazônicos", especificamente sobre Extrativismo Vegetal, sendo necessário experimentar diferentes tipos de abordagem dos alunos para melhor entendimento sobre a temática, assim a proposta é a cartilha bem ilustrada e simplificada sobre o assunto que desenvolvemos ao longo desse trabalho.

\section{Referências}

GONÇALVES, Walter Porto Gonçalves: Amazônia, Amazônias. São Paulo: Contexto. 2001.

HÉBETTE, Jean: A ocupação humana recente da microrregião de Marabá. In: Hébette, J. (Org.). Cruzando a fronteira: 30 anos de estudo sobre o campesinato na Amazônia. v. IV. Belém, PA: EDUFPA, 2004. p. 63-71.

LESSA, S. Lukács e a ontologia: Uma Introdução. Outubro, São Paulo, n. 5, p. 83-100, jul./dez. 2001.

RÊGO, José Fernandes: Amazônia: Do Extrativismo Ao Neoextrativismo. Ciência hoje, v. 25, n. 146, p. 62-65, 1999.

SILVA, Danielle Wagner et al.: Extrativismo e desenvolvimento no contexto da Amazônia brasileira. Desenvolvimento e Meio Ambiente, v. 38, 2016.

SILVA, Wilma Marinho Craveiro; ROCHA, Eremilda Silveira; DA SILVA, Heloane do Socorro Sousa. O Extrativismo Vegetal Na Amazônia: Os Desafios Desta Atividade Diante De Uma Educação Ambiental. Examãpaku, v. 7, n. 1, p. 76-90, 2014. 